This document is published in:

Journal of Industrial Economics (2003), 51(3), 271-293.

DOI: 10.1111/1467-6451.00201

(C) 2003 Blackwell Publishing Ltd. 


\title{
TACIT COLLUSION IN REPEATED AUCTIONS: UNIFORM VERSUS DISCRIMINATORY*
}

\author{
Natalia FABra $\dagger$
}

\begin{abstract}
Within an infinitely repeated game, I compare the level and conduct of collusion under uniform and discriminatory auctions. For this purpose, I characterize the optimal collusive schemes and sets of sustainable profits under these auction formats. I show that uniform auctions facilitate collusion more than discriminatory auctions: the optimal penal code is equally severe under the two formats; but bidders' deviation incentives are weaker in uniform auctions given that the payoff irrelevant bids can be used to relax the enforcement problem. This discussion is particularly relevant after the recent reforms in the electricity industry in England \& Wales, and elsewhere.
\end{abstract}

\section{INTRODUCTION}

Collusion APPEARs to Be a pervasive problem in many auctions. There has been evidence of collusion in auctions for public work contracts (McMillan [1991]), highway construction (Porter and Zona [1993]), natural resources (Baldwin, Marshall and Richard [1997]), and the distribution of school milk (Pesendorfer [2000]). Both theory and practice suggest that collusion is a particularly critical issue when auctions are repeated frequently. In a dynamic setting, bidders may learn to coordinate their strategies, and hence compete less aggressively with each other in order to raise profits over the level that would be attained in a static setting. However, the sustainability of collusion is faced with an enforcement problem. Bidders may find it in their private interest to deviate from the recommended strategy, i.e., to cheat. As is well known, for collusion to be sustainable, the threat of future punishments should be strong enough so as to discourage bidders from cheating.

The aim of this paper is to assess how different auction formats affect the possibilities for enforcing collusion in a dynamic setting. With few

\footnotetext{
* I benefitted from the comments of Massimo Motta, Pierpaolo Battigalli, Sandro Brusco, Roberto Burguet, Jorge Fabra, Giulio Federico, Nils-Henrik von der Fehr, David Harbord, Giovanni Maggi, Patrick Rey, Carlo Scarpa, Juan Toro, Catherine Wolfram, the editor and two anonymous referees. All errors are mine. Earlier versions of this paper were written at the European University Institute (Florence), Nuffield College (Oxford) and the IDEI (Toulouse).

$\dagger$ Author's affiliation: Departamento de Economia, Universidad Carlos III de Madrid, Calle Madrid 126, 28903 Getafe (Madrid), Spain.

email:nfabra@eco.uc3m.es
} 
exceptions, ${ }^{1}$ the previous literature on collusion in auctions has restricted attention to the analysis of one-shot auctions (von Ungern-Sternberg [1988], McAfee and McMillan [1992] and Pesendorfer [2000]). These models abstract from the enforcement problem by assuming that bidders are sufficiently patient so that the adherence to the collusive scheme is always guaranteed. This assumption is not suitable for comparing the sustainability of collusion across auction formats since it would hide their differences in terms of the costs and gains from cheating. By explicitly modelling the repetition of auctions, our paper is able to highlight these differences, which will be shown to be crucial for the sustainability of collusion.

We restrict attention to the analysis of collusion under two commonly used auction formats: the uniform-price and the discriminatory auction. Under both auction formats, bidders submit supply schedules ${ }^{2}$ which specify the prices they are willing to receive for every unit of the good, and the units are allocated to the bidders who submitted the lowest bids. The two auction formats differ in the price that each bidder receives for the units it is awarded: in the uniform-price auction, all bidders receive the same price, equal to the highest accepted bid, whereas in the discriminatory auction each bidder receives his individual price offers.

One motivation for focusing on the analysis of uniform-price and discriminatory auctions is the ongoing debate in electricity markets about the desirability of adopting either one of these two auction formats. ${ }^{3}$ Electricity markets differ in several aspects, but to date all have been organized as uniform-price auctions. The new reforms recently introduced in England and Wales have departed from this common feature, by switching from a uniform-price to a discriminatory auction. The UK regulatory authorities claim that uniform-price auctions are more subject to strategic manipulation than discriminatory auctions, and therefore expect that the switch in the auction format will offer lower prices from more competitive trading. (See Ofgem [2002] for a comparison of the pattern of prices before and after the reform).

This claim is supported by several papers that have compared uniformprice and discriminatory auctions in a static setting (see Back and Zender [1993], Klemperer [2002], Fabra, von der Fehr and Harbord [2002]; Goswami, Thomas and Rebello [1996] provide experimental evidence).

\footnotetext{
${ }^{1}$ See Athey and Bagwell [2001], Aoyagi [2000] and Skrzypacz and Hopenhayn [1999].

${ }^{2}$ Our model is specified in terms of selling but, with the appropiate change in signs, it can be translated into a model of buying.

${ }^{3}$ A similar debate has characterized Treasury auctions. Auctions for Treasury debt, both in Europe and the USA, have typically been of the discriminatory type. However, after a campaign led by Merton Miller and Milton Friedman, the US Treasury has been experimenting with uniform-price auctions. For a particularly enlightening discussion of this debate, see Binmore and Swierzbinski [2001]; for an empirical analysis, see Nyborg and Sudaresan [1996].
} 
It has been shown that uniform-price auctions relax competition more than discriminatory auctions because of the main feature that distinguishes both types of auction formats. Namely, in the uniform-price auction, bidders are only concerned about a single point in their bidding functions, the one corresponding to the market price, whereas bidders in the discriminatory auction care about their entire bidding schedules. This implies that in the uniform-price auction, the inframarginal bids are pay-off irrelevant and can be chosen so as to inhibit competition at the margin. For instance, if a bidder submits a very steep bidding curve (i.e., relatively low inframarginal bids), the residual demand curve facing his rivals will also be steep. A steep residual demand curve implies that the opportunity cost of expanding production beyond the bidder's equilibrium quantity is high, so that artificially high prices can be supported in equilibrium. In contrast, these high-price equilibria cannot be supported in the discriminatory auction because the low inframarginal bids cannot be used as costless threats.

Our results show that the differences between uniform-price and discriminatory auctions are strengthened when the possibilities of tacit collusion are taken into account. To the best of our knowledge, this is the first paper that provides such an analysis by explicitly modelling the repetition of auctions.

We construct an infinitely repeated game of capacity-constrained price competition among symmetric firms. In every period, competition takes place by firms submitting a bid which specifies the minimum price at which they are willing to supply their output up to capacity. The auctioneer ranks firms in increasing order on the basis of their bids. The price that each successful bidder receives for his output depends on the auction format in place: either a uniform-price auction, under which firms receive the highest accepted price offer, or a discriminatory auction, under which firms are paid according to their individual price offers.

Within this set-up, we show that the lowest value of sustainable profits (i.e., the value of the optimal penal code) coincides across auction formats. The highest level of sustainable profits differs however, and it is (weakly) higher in the uniform-price auction; the comparison is strict when capacities are not too large relative to demand, and bidders are not too patient. The main reason underlying this result is that in the uniformprice auction, whenever the two firms are called to produce, the low bid is pay-off irrelevant. The low-bid can thus be used to relax the enforcement problem and thereby to raise collusive profits over the highest level that is sustainable in the discriminatory auction, in which both bids are pay-off relevant.

This fact also has implications for the characterization of bidders' optimal collusive conduct along the equilibrium path. In the discriminatory auction firms cannot do better than to collude on equal bids, whereas firms in the uniform-price auction find it optimal (for some capacity values) to bid 
asymmetrically and to alternate the identity of the low and high bidders in deterministic turns. In the uniform-price auction, asymmetric bidding minimizes firms' one-shot deviation gains, and pure bid rotating serves to reward the firm with the strongest incentives to deviate with the largest possible market share in the immediate future. Asymmetric bidding is not optimal in the discriminatory auction since it would enhance bidders' incentives to deviate.

To sum-up, our results imply that uniform-price auctions facilitate collusion more than discriminatory auctions in the sense that the former allow bidders to sustain collusive profits that are not reachable as a Subgame Perfect Equilibrium of the latter.

The remainder of the paper is organized as follows. Section II describes the basic model. Section III analyzes the one-shot game and section IV explores the infinitely repeated game under the two auction formats. Section $\mathrm{V}$ concludes by discussing the robustness of the results. The Appendix contains most of the proofs.

\section{THE MODEL}

We focus on a stylized model with two symmetric firms, ${ }^{4}$ which compete to sell an homogenous good to the market. Each firm is endowed with productive capacity $k$, which is assumed to be perfectly divisible. Marginal costs of production are normalized to zero up to capacity, whereas production above capacity is impossible (i.e., infinitely costly).

The market demand function is represented by $D(P)$ and it is assumed to satisfy the following standard assumptions: $D(P)$ is a continuous, bounded function; there exists a price $\bar{P}>0$ such that $D(P)=0$ if and only if $P \geq \bar{P} ; D(P)$ is decreasing in $P \forall P \in[0, \bar{P}],{ }^{5}$ and $P D(P)$ is strictly quasiconcave in $P \forall P \in[0, \bar{P}]$.

These assumptions guarantee that there exists a unique price $P^{m}$ that maximizes joint profits, and that whenever $D(0)>k$, there exists a unique price $P^{r}$ which maximizes a firm's profits from serving the residual demand, subject to firms' capacity constraints. These prices will be respectively referred to as the monopoly and residual monopolist's prices, and are formally

\footnotetext{
${ }^{4}$ The duopoly assumption is without loss of generality. The results of this paper could easily be generalized to the (symmetric) oligopoly case.

${ }^{5}$ The assumption that the demand function is downward sloping is important. Fabra, von der Fehr and Harbord [2002] show that with an inelastic demand function, the monopoly outcome could be sustained (for a large set of parameter values) as a one-shot Nash equilibrium in a uniform-price auction. Since only profit levels below that level can be sustained in the discriminatory auction, this would imply that the conclusion that uniform-price auctions facilitate collusion would arise even without the repetition of auctions. That is, by considering a price-responsive demand function, we are taking the assumption that less favors our results.
} 
defined as

$$
\begin{aligned}
P^{m} & =\max \left\{\arg \max _{P} P D(P), D^{-1}(2 k)\right\} \\
P^{r} & =\max \left\{\arg \max _{P} P[D(P)-k], D^{-1}(2 k)\right\}
\end{aligned}
$$

The timing of the game proceeds as follows. Each firm simultaneously and independently submits a bid specifying the minimum price at which it is willing to supply its production up to capacity, $b_{i} \in \Re_{+}, i=1,2$. We use $b \equiv\left(b_{1}, b_{2}\right)$ to denote the bid profile. On the basis of this bid profile, the auctioneer calls firms to produce. If firms submit different bids, the low bidder is despatched first. If its capacity is not sufficient to satisfy the total demand at the low price, the high bidder will be called to produce the residual demand, i.e., total demand at the high price minus its rival's capacity. If firms submit equal bids, then firms split the market equally. Formally, the quantity allocated to firm $i, i=1,2, i \neq j$, denoted by $q_{i}(b)$, is given by 6

$$
q_{i}(b)=\left\{\begin{array}{lll}
\min \left\{D\left(b_{i}\right), k\right\} & \text { if } \quad b_{i}<b_{j} \\
\min \left\{\frac{1}{2} D\left(b_{i}\right), k\right\} & \text { if } \quad b_{i}=b_{j} \\
\min \left\{\max \left\{0, D\left(b_{i}\right)-k\right\}, k\right\} & \text { if } \quad b_{i}>b_{j}
\end{array}\right.
$$

The highest accepted bid in the auction is referred to as the market price, and it is denoted by $P(b)$. For a given bid profile $b \equiv\left(b_{i}, b_{j}\right), i=1,2, i \neq j$, it can be expressed as

$$
P(b)=\left\{\begin{array}{lll}
b_{j} & \text { if } & q_{j}(b)>0 \text { and } b_{i} \leq b_{j} \\
b_{i} & \text { if } & q_{j}(b)=0 \text { and } b_{i} \leq b_{j}
\end{array}\right.
$$

At the end of the game, each firm receives its profits. The auctioneer announces the market price but does not disclose any information concerning firms' price offers nor quantity shares. Both firms are assumed to be risk neutral, and hence aim to maximize their expected payoff. We make the standard assumption that all aspects of the game are common knowledge.

Throughout the paper, we shall consider two auction formats: discriminatory and uniform-price auctions. Both the timing of the game, and the quantities allocated to each firm for a given bid profile are independent of the auction format. Payments to firms depend upon the auction format however. The price received by a firm for its output is equal to its own bid in the discriminatory auction, and equal to the market price in the

\footnotetext{
${ }^{6}$ The rationing scheme implicit in this formulation is often referred to as the efficient rationing scheme; it is 'efficient', in the sense that the consumers that value the good most are served first. It has appeared, inter alia, in Brock and Scheinkman [1985], Kreps and Scheinkman [1983] and Staiger and Wolak [1992].
} 
uniform-price auction. Hence, for a given bid profile $b \equiv\left(b_{i}, b_{j}\right)$, firm $i$ 's profits, $i=1,2, i \neq j$, in the discriminatory auction, $\pi_{i}^{d}(b)$, and in the uniformprice auction, $\pi_{i}^{u}(b)$, can be expressed as,

$$
\begin{aligned}
& \pi_{i}^{d}(b)=b_{i} q_{i}(b) \\
& \pi_{i}^{u}(b)=P(b) q_{i}(b),
\end{aligned}
$$

where $q_{i}(b)$ and $P(b)$ are respectively determined by (2) and (3).

\section{THE ONE-SHOT GAME}

The main objective of this paper is to compare the sustainability of collusive outcomes across auction formats within an infinitely repeated game. As is well understood, there are two main factors affecting the sustainability of collusion: the severity of the (credible) punishment threat and the value of the one-shot deviation gains. The stronger the punishment threat and the weaker the incentives to deviate, the easier it is to sustain collusion. Hence, in order to characterize the most profitable collusive equilibrium, one has to first, $(i)$ find the lowest level of profits a firm can be credibly held down to; and second, (ii) identify the pairs of bids which, for a given level of joint profits, minimize firms' one-shot deviation gains. With these purposes, we devote this section to the analysis of the one-shot game.

Firm $i$ 's, $i=1,2$, minmax profit, denoted $\pi$, is defined as the least amount that firm $j, j \neq i$, can hold firm $i$ 's profits down to. It is easy to see that this occurs when firm $j$ is bidding all its capacity at zero, i.e. $\underline{\pi}=\max \left\{0, \arg \max _{b_{i}}\left[D\left(b_{i}\right)-k\right] b_{i}\right\}, i=1,2$. The following Lemma characterizes $\underline{\pi}$ under the two auction formats.

Lemma 1. Under uniform-price and discriminatory auctions, minmax profits can be characterized as follows:

(i) If $k \geq D(0)$, minmax profits equal zero.

(ii) If $k<D(0)$, minmax profits are equal to the profits of the residual monopolist, $P^{r}\left[D\left(P^{r}\right)-k\right]$.

Proof. It follows by definition of $P^{r}$, as given in (1).

Lemma 1 shows that, unless that a single firm's capacity is enough to cover all demand at marginal cost, a firm can always secure positive profits by bidding at the residual monopolist's price. Given that in this case the residual monopolist's price exceeds zero, the price received by the minmaxed firm equals the market price. Therefore, minmax profits coincide across auction formats. 
The following Lemma characterizes a firm's profits at its best response to any arbitrary bid of the rival.

Lemma 2. Under the two auction formats, firm $i$ 's profits at its best response to any arbitrary bid $b_{j} \in\left[0, P^{m}\right]$ are equal to $\sup _{b_{i}<b_{j}} b_{i} \min \left\{k, D\left(b_{i}\right)\right\}$ if $b_{j}>\frac{\pi}{\bar{k}}$, and are equal to its minmax profits $\underline{\pi}$ otherwise, $i=1,2, i \neq j$.

\section{Proof. See the Appendix.}

The intuition underlying the proof of Lemma 2 is as follows. On the one hand, a firm might consider undercutting the rival's bid in order to increase its production with only a negligible effect (if any) on the market price. On the other hand, if bidding a higher price leaves the competitor capacity constrained, a firm might also consider maximizing its profits over the residual demand. When the rival's price is high, undercutting it is more profitable, but when the rival's price is low, becoming the residual monopolist becomes more profitable even if this could involve selling below capacity.

We conclude that by making the bid of one firm sufficiently low, the remaining firm's best response profits can be driven down to the residual monopolist's profits, which coincide with the minmax. These results apply equally under the two auction formats given that, at its best response, a firm's bid in the discriminatory auction coincides with (or is arbitrarily close to) the market price.

We define firm $i$ 's, $i=1,2, i \neq j$, one-shot deviation gains from an arbitrary bid profile $\left(b_{i}, b_{j}\right)$ as the difference between firm $i$ 's profits at its best response to $b_{j}$ and the profits it would get at the bid profile $\left(b_{i}, b_{j}\right)$, i.e. $\sup _{b_{i}} \pi_{i}\left(b_{i}, b_{j}\right)-\pi_{i}\left(b_{i}, b_{j}\right)$. Building on Lemma 2, the following Lemma identifies the bid profile(s) that minimizes firms' one shot deviation gains among the sets of bid profiles yielding a given level of joint profits.

Lemma 3. Consider the set of bid profiles that yield joint profits $P D(P) \in\left(2 \pi, P^{m} D\left(P^{m}\right)\right]$. The bid profile(s) that minimizes the maximum between firm 1 and 2's one-shot deviation gains can be characterized as follows:

(i) In the discriminatory auction, it is symmetric, with $b_{i}=P, i=1,2$.

(ii) In the uniform-price auction, if $k<D(P)$, it is asymmetric, with $b_{i}=P$ and $b_{j} \leq \frac{\pi}{\bar{k}}, i=1,2, i \neq j$; it is symmetric otherwise.

Proof. See the Appendix.

When the capacity of a single firm is not enough to satisfy all demand, the two auction formats are not equivalent in terms of the bid profiles that minimize firms' one-shot deviation gains. The different patterns derive from 
the main feature that distinguishes both auction formats. Namely, in the uniform-price auction all firms (conditional upon being despatched) are paid the price offered by the marginal firm rather than their own bid, as it is the case in the discriminatory auction.

This implies that in the uniform-price auction, it suffices that one firm bids at $P$ and the other firm bids prices no greater than $P$ for joint profits to equal $P D(P)$. If firms bid asymmetrically, the low bidder would have no incentives to deviate, given that it sells all its capacity at the rival's price. Furthermore, given that the low bid is pay-off irrelevant, it can be set 'low' enough so that the high bidder finds it optimal to deviate by charging the residual monopolist's price rather than to undercut the low bid (Lemma 2). This drives the high bidder's deviation profits to the minmax, and thereby minimizes its one-shot deviation gains.

The incentive structure induced by asymmetric bidding in the uniformprice auction cannot be replicated in the discriminatory auction. Given that both bids are pay-off relevant, making one bid sufficiently 'low' in order to drive the high-bidder's deviation profits to its minmax would come at the cost of reducing joint profits below $2 \pi{ }^{7}$. With both firms bidding 'high' prices, either firm could increase its profits by slightly undercutting the rival in order to sell at capacity at the rival's price. Making bids symmetric allows reducing both firms' deviation profits and increasing the equilibrium profits of at least one-firm with respect of the case in which bids are asymmetric. This implies that firms' one-shot deviation gains in the discriminatory auction are minimized through symmetric bidding.

From Lemma 3, it follows directly that firms' one-shot deviation gains in the uniform-price auction can be made (weakly) lower than in the discriminatory auction, where the comparison is strict for the cases in which asymmetric bidding is optimal in the uniform-price auction. This is formally stated in the Proposition below.

Proposition 1. Assume that firms play the bid profiles identified in Lemma 3 . Then, $(i)$ the maximum between firm 1 and 2's one-shot deviation gains is strictly lower in the uniform-price auction than in the discriminatory auction if and only if $k<D(P)$, and (ii) it is equal otherwise.

\section{Proof. It follows from the proof of Lemma 3.}

The last Proposition of this section shows that, under the two auction formats, both firms' profits can be driven down to the minmax through Nash equilibrium play.

\footnotetext{
${ }^{7}$ The high bidder's profits are no greater than $\pi$. Therefore, the low bidder, which is selling at capacity at its own price, must bid above $\frac{\pi}{\bar{k}}$ for joint profits to be greater than $2 \pi$.
} 
Proposition 2. Under the two auction formats, both firms' profits are driven down to the minmax at the unique symmetric one-shot Nash equilibrium.

\section{Proof. See the Appendix.}

The characterization of the one-shot Nash equilibria in the uniform-price and discriminatory auctions crucially depends on the relationship between demand and firms' capacities. When capacities are such that demand at marginal cost exceeds the capacity of a single firm (case ( $i$ ) in Lemma 1), the unique symmetric Nash equilibrium under the two auction formats involves firms' bidding at marginal cost, thus earning zero profits. This is just the Bertrand equilibrium.

When demand at marginal cost exceeds the capacity of a single firm (case (ii) in Lemma 1), the nature of the one-shot Nash equilibria depends on whether a single firm has enough capacity to satisfy all demand at its best response to the rival selling at capacity, or not (i.e., on whether the residual monopolist's price lies above or is equal to $\left.D^{-1}(2 k)\right)$.

When, at the residual monopolist's price, both firms would sell at capacity, the unique symmetric Nash equilibrium under the two auction formats involves both firms' bidding at $D^{-1}(2 k)$, thus earning minmax profits. If firms tie at prices below $D^{-1}(2 k)$, either firm could increase its profits by bidding above that level while still selling at capacity. If both firms tie at prices above $D^{-1}(2 k)$, capacities would not be binding; therefore, either firm would find it optimal slightly to undercut the rival's bid in order to sell at capacity, with no effect on the market price in the uniform-price auction, and only a negligible reduction in the price received in the discriminatory auction.

In the remaining case, in which the residual monopolist's price is larger than $D^{-1}(2 k)$, a symmetric equilibrium in pure strategies fails to exist. Following Lemma 2, if firms tie at prices no greater than $\frac{\pi}{k}$, either firm would be better off by bidding at the residual monopolist's price; if firms tie at prices above $\frac{\pi}{k}$, then either firm could increase its profits by slightly undercutting the rival. Thus the unique symmetric equilibrium under the two auction formats involves mixed strategy pricing, with firms randomizing their offer prices within a support bounded above by the residual monopolist's price. Given that when a firm is bidding at this upper bound, the rival is bidding below that level with probability one and given that all prices in the support yield an equal level of profits, both firms' expected equilibrium profits coincide with the residual monopolist's profits, i.e., the minimax.

With these results, we are now ready to analyze the infinitely repeated game. 


\section{THE INFINITELY REPEATED GAME}

In this section, we explore an infinitely repeated version of the stage game described above. In the infinitely repeated game, a strategy for firm $i, i=1,2$, is an infinite sequence of functions $S_{i}=\left(S_{i}(1), S_{i}(2), \ldots, S_{i}(t), \ldots\right)$, where $S_{i}$ (1) is a determinate initial bid, and $S_{i}(t)$ is a function that maps the market prices and the quantities allocated to firm $i$ in periods $1,2, \ldots, t-1$ into a bid $b_{i}(t)$ for firm $i$ in period $t$. Recall that only market prices are observed, so that the strategy of one firm cannot be conditioned on the bids submitted by its rival in previous periods. The strategy profile $\left(S_{1}, S_{2}\right)$ induces a path of bid profiles $(b(1), b(2), \ldots, b(t), \ldots)$, where $b(1)=\left(S_{1}(1), S_{2}(1)\right)$, and given $(b(1)$, $b(2), \ldots, b(t-1))$, firm $i$ 's bid in period $t$ is a function of the partial history of the game with length $t-1$ observed by firm $i$, i.e., $b_{i}(t)=S_{i}\left(q_{i}(b(1))\right.$, $\left.P(b(1)), \ldots, q_{i}(b(t-1)), P(b(t-1))\right)$. The payoff function for firm $i, i=1,2$, is the sum of its discounted profits, where $\delta \in(0,1)$ is firms' common discount factor.

One of the aims of this analysis is to characterize the sets of profits that are supportable by a Subgame Perfect Equilibrium under uniform-price and discriminatory auctions. Proposition 2 guarantees that the symmetric Nash equilibrium yields minmax profits to both firms. Since lower profits would not be sustainable, the minmax level represents the lower bound of the set of sustainable profits. To characterize the upper bound of this set, assume throughout the remainder of the paper that firms select a path of bid profiles so as to maximize joint profits, subject to the constraint that such a path be sustainable by a Subgame Perfect Equilibrium. A path is supportable by a Subgame Perfect Equilibrium if and only if it is supportable by an optimal penal code, e.g., the infinite reversion to the symmetric Nash equilibrium. ${ }^{8}$ The associated trigger strategy profile can be expressed as, for $i=1,2$,

$$
\begin{aligned}
& S_{i}(1)=b_{i}^{c}(1) \\
& \text { For } t \in\{2,3, \ldots,\}, \\
& S_{i}(t)= \begin{cases}b_{i}^{c}(t) & \text { if } P(b(\tau))=P\left(b^{c}(\tau)\right) \text { and } \\
q_{i}(b(\tau))=q_{i}\left(b^{c}(\tau)\right), \forall \tau \in\{1, \ldots, t-1\}, & \text { otherwise }\end{cases}
\end{aligned}
$$

where, as defined in (3), $P(b(t))$ is the market price in period $t$; as defined in (2), for a given bid profile $b(t), q_{i}(b(t))$ is the quantity allocated to firm $i$ in

\footnotetext{
${ }^{8}$ Similar results would be obtained if we allowed the punishment phase to last for a finite number of periods, just as long as such a penal code is optimal, i.e., the discounted sum of punishment profits must be the same as if firms were minmaxed in every period. Therefore, for the current purposes of the analysis, we are unconcerned about the particular shape of the punishment phase. For an analysis of optimal penal codes in price-setting supergames with capacity constraints, see Lambson [1988].
} 
period $t ; b_{i}^{c}(t) \in\left[0, P^{m}\right]$ is firm $i$ 's collusive bid in period $t$; and $b_{i}^{N}$ is firm $i$ 's (possibly random) bid at the symmetric one-shot Nash equilibrium.

In words, the strategy profile (4) prescribes firms to submit the collusive bid in period 1 and to follow the collusive path as long as both firms have done the same in all previous periods. If a firm deviates, both firms are called to start playing the symmetric Nash equilibrium in all periods after the deviation has taken place.

It is straightforward to show that the necessary and sufficient conditions for the strategy profile in (4) to form a Subgame Perfect Equilibrium of the infinitely repeated game are, for all firms, $i=1,2, i \neq j$, and all periods $t \geq 1$,

$$
\sum_{\tau=t+1}^{\infty} \delta^{\tau-t} \pi_{i}\left(b^{c}(\tau)\right)-\left[\sup _{b_{i}} \pi_{i}\left(b_{i}, b_{j}^{c}(t)\right)-\pi_{i}\left(b^{c}(t)\right)\right] \geq \frac{\delta}{1-\delta} \underline{\pi} .
$$

Intuitively, the incentive compatibility constraint above says that what a firm loses by deviating (i.e., the discounted value of future collusive profits net of the one-shot deviation gain) should at least be equal to the net present value of the stream of minmax profits that the deviant firm would receive along the (optimal) punishment path.

Note that the right hand side of (5) is constant and equal for both firms. Thus the incentive compatibility constraint that binds first, is that of the firm for whom the left hand side of (5) is the lowest (as long as such a firm has strictly positive one-shot deviation gains). Accordingly, for a given level of joint profits, the optimal collusive scheme(s) will be the one(s) that maximizes the difference between the discounted sum of profits under collusion and the one-shot deviation gains of the firm for which this difference is the smallest.

The following Proposition characterizes the optimal collusive schemes under the two auction formats.

Proposition 3. Consider the paths of bid profiles that yield joint profits $P D(P) \in\left(2 \underline{\pi}, P^{m} D\left(P^{m}\right)\right]$ in every period.

(i) In the discriminatory auction, the optimal collusive scheme involves symmetric bidding in all periods, i.e., $b_{i}(t)=P, i=1,2, t \geq 1$.

(ii) In the uniform-price auction, the optimal collusive scheme involves symmetric bidding in all periods if and only if $k \geq D(P)$, and asymmetric bidding and pure bid rotating, with $b_{i}(t)=b_{j}(t+1) \leq \frac{\pi}{\bar{k}}$ and $b_{j}(t)=b_{i}$ $(t+1)=P, i=1,2, i \neq j, t \geq 1$, otherwise.

Proof. See the Appendix.

Note that, for some capacity values, the optimal collusive scheme in the uniform-price auction involves asymmetric bidding, with one firm 
submitting a sufficiently low price, ${ }^{9}$ and firms rotating the identity of the low and high bidders in deterministic turns. This collusive scheme simultaneously minimizes firms' one-shot deviation gains (Lemma 3 ) and serves as a transfer role rewarding the high bidder with the largest possible market share in the future.

We can now build on the previous results to compare the maximum level of joint profits that, for a given discount factor, can be sustained under the two auction formats.

Proposition 4. For given $\delta \in(0,1)$, the highest sustainable profit level in the uniform-price auction (weakly) exceeds the one in the discriminatory auction; the comparison is strict if and only if $k<D(0)$ and monopoly profits are not sustainable in the discriminatory auction.

\section{Proof. See the Appendix.}

The proof of Proposition 4 follows from our previous results. Firstly, firms in the discriminatory auction cannot do better than to collude on symmetric bid profiles. Since symmetric bidding induces the same incentives under the two auction formats, firms in the uniform-price auction can at least sustain the same profit level as in the discriminatory auction.

For capacity values such that demand at marginal cost exceeds the capacity of a single firm, the highest price that can be sustained in the discriminatory auction exceeds the capacity a single firm. This implies that, in the uniform-price auction, the high bidder's incentive compatibility constraint would be satisfied with slack when evaluated at the optimal collusive scheme yielding the maximum profit level that can be sustained in the discriminatory auction. If such a level is below monopoly profits, firms in the uniform-price auction can raise collusive profits above the most collusive profit level in the discriminatory auction while still satisfying firms' incentive compatibility constraints.

Last, when demand at marginal cost does not exceed the capacity of a single firm, the two auctions are strategically equivalent, and thus result in an equal level of sustainable profits.

To conclude, these results imply that the uniform-price auction facilitates collusion in the sense that it allows bidders to obtain equilibrium profit levels that are not sustainable as a Subgame Perfect Equilibrium of the discriminatory auction.

\footnotetext{
${ }^{9}$ The same incentive structure could be replicated by making the low bidder randomize its bids as in the symmetric one-shot Nash equilibrium for $k$ values such that $k<D(0)$ and $P^{r}>D^{-1}(2 k)$. Note that in this case, firms' one-shot deviation gains are unaltered, as the low bidder has no incentives to deviate and the high bidder cannot obtain deviation profits greater than its minmax. This reduces the disparity between bids and may be preferable in the presence of a vigilant competition authority that becomes suspicious when bids are too asymmetric. See section $\mathrm{V}$ for more on this.
} 


\section{CONCLUDING REMARKS}

In this paper we have analyzed an infinitely repeated game of capacityconstrained price competition among two symmetric firms. We have used this model to characterize the optimal collusive schemes and sets of profits that can be sustained under two commonly used auction formats: the uniform-price and discriminatory auctions.

The model predicts that firms in the discriminatory auction cannot do better than to collude on symmetric equilibria. In contrast, firms in the uniform-price auction find it optimal (for some capacity values) to implement collusive schemes characterized by asymmetric bidding and bid rotating. These schemes reduce the profitability of defections and increase the value of future cooperation more than symmetric bidding. Therefore, for a given discount factor, the maximum level of sustainable profits in the uniform-price auction is (weakly) higher than the one that arises in any equilibrium of the discriminatory auction. Thus, uniform-price auctions (weakly) facilitate tacit collusion.

The last remarks concern the robustness of the results to relaxing some of our simplifying assumptions. ${ }^{10}$ First, let us allow firms (as it is the case in electricity auctions) to submit different bids for different blocks of output, instead of a single bid. It is possible to show that our previous results concerning the comparison of collusive possibilities across auction formats remain valid. To see this, note that in the uniform-price auction firms' deviation profits are driven down to the minmax only if one firm bids all its units at sufficiently low prices. This makes it unprofitable for the lowbidding firm to deviate, and for the high bidding firm to undercut the low bids. With one firm's becoming a monopolist over the residual demand, it is inconsequential whether the rival's capacity is divided into one or several units. Last, with the remaining firm's earning higher equilibrium profits than its rival, the optimal collusive scheme involves pure-bid rotating, as before.

Second, we have assumed that market conditions remain constant over time. Suppose instead (similarly to Staiger and Wolak [1992]), that demand is subject to stochastic shocks that are realized and observed before firms make their pricing decisions. It is possible to show that demand uncertainty facilitates collusion more under the uniform-price auction than under the discriminatory auction. In the uniform-price auction, firms' ability to reduce their one-shot deviations through asymmetric bidding has a double effect on the profitability of collusion: for some demand realizations, it allows raising collusive prices over the ones sustainable through symmetric bidding; this, in turn, leads to an increase in the future losses from cheating at all other demand realizations. This indirect effect implies that collusive prices can be

\footnotetext{
${ }^{10}$ The formal statements and proofs for the following two results are available at The Journal of Industrial Economics' website.
} 
raised at all demand realizations, and not only at those at which the optimal collusive schemes are asymmetric.

Last, we have not considered the case in which collusive behavior is subject to legal prosecution. An analysis of this issue would face us with the following questions: could the legal authority uncover the conspiracy when bidders collude on the optimal schemes identified above? If so, would the ranking across auctions be altered if bidders tried to reduce the probability of detection by making their strategies 'less visible'? ${ }^{11}$ In the discriminatory auction, for some capacity values, the probability that bidders submit equal bids at a one-shot Nash equilibrium is zero. Thus, the existence of a collusive agreement could be inferred from the fact that bids are identical. The detection of collusion would be harder in the uniform-price auction given that asymmetric bidding and market share instability also arise at the one-shot Nash equilibria (see Fabra, von der Fehr and Harbord [2002]). Furthermore, even if bidders departed from asymmetric bidding and pure bid rotating, the most collusive equilibrium would still be more profitable than in the discriminatory auction. For instance, bidders could depart from pure bid rotating by colluding on the symmetric correlated equilibrium (i.e., the probability of playing the role of the high and low bidder is equal for both firms and independent of a firm's previous period's role). This scheme would reduce the maximum level of sustainable profits (given that the high bidder's losses from cheating would be smaller) but it would still imply that collusion is more profitable than under the discriminatory auction (given the weaker incentives to deviate achieved through asymmetric bidding). Also, the degree of bid asymmetry could be reduced by letting the low bidder bid as in the one-shot Nash equilibrium, i.e., depending on the capacity values, either randomizing its bid or charging the maximum price at which both firms sell at capacity. This would not reduce the highest level of sustainable profits since the high bidder's profits at its best response to the low bidder's strategy would also equal minmax profits.

To conclude, the interest of this analysis from the policy oriented perspective is two-fold: firstly, from a regulation point of view, it sheds some light on the design of those market rules that reduce the scope for collusion; and secondly, from the antitrust point of view, it identifies the observable differences between competitive and collusive conduct and can thereby be used to tailor the antitrust policies to the detection and mitigation of collusion.

\section{APPENDIX}

\section{Proofs of Lemmas and Propositions}

Proof of Lemma 2. Assume $b_{j}>\frac{\pi}{\bar{k}}$. If $D\left(b_{j}\right)>k$, then by slightly undercutting $b_{j}$ firm $i$ would get profits $\sup _{b_{i}<b_{j}} b_{i} k$. These profits are greater than what it would get by tying

\footnotetext{
${ }^{11}$ See LaCasse [1995] for a formal analysis of this issue in a simple auction model.
} 
at $b_{j}, b_{j} \frac{D\left(b_{j}\right)}{2}$, and exceed the highest level of profits that it could make by bidding above $b_{j}, \underline{\pi}$. If $D\left(b_{j}\right) \leq k$, then by slightly undercutting $b_{j}$ firm $i$ would get profits $\sup _{b_{i}<b_{j}} b_{i} D\left(b_{i}\right)$, which exceed the profits that it would make by tying at $b_{j}, b_{j} \frac{D\left(b_{j}\right)}{2}$, or by bidding above $b_{j}$, zero. Thus $\sup _{b_{i}} \pi_{i}\left(b_{i}, b_{j}\right)=\sup _{b_{i}<b_{j}} b_{i} \min \left\{k, D\left(b_{i}\right)\right\}$.

Assume $b_{j} \leq \frac{\pi}{\bar{k}}$. Then, by bidding above $b_{j}$ firm $i$ could get profits $\underline{\pi}$, which are (weakly) greater than the profits that it would get from undercutting $b_{j}$, $\sup _{b_{i}<b_{j}} b_{i} \min \left\{k, D\left(b_{i}\right)\right\}$, or from tying at $b_{j}, b_{j} \min \left\{k, \frac{D\left(b_{j}\right)}{2}\right\}$. Thus $\sup _{b_{i}} \pi_{i}\left(b_{i}, b_{j}\right)=\underline{\pi}$.

Proof of Lemma 3. Let $\Gamma_{i}\left(b_{i}, b_{j}\right), i=1,2, i \neq j$, be firm $i$ 's one-shot deviation gain, i.e.

$$
\Gamma_{i}\left(b_{i}, b_{j}\right) \equiv \sup _{b_{i}} \pi_{i}\left(b_{i}, b_{j}\right)-\pi_{i}\left(b_{i}, b_{j}\right) .
$$

\section{(i) Discriminatory auction:}

We want to show that, among the set of bid profiles that yield joint profits $P D(P) \in\left(2 \pi, P^{m} D\left(P^{m}\right)\right]$, the asymmetric bid profiles with $b_{1} \neq b_{2}$ would give higher one-shot deviation gains than the symmetric bid profiles with $b_{1}=b_{2}$, for at least one firm.

W.1.o.g. index firms such that $b_{1} \leq b_{2}$. First, assume $k \geq D(P)$. Hence, the bid profiles yielding joint profits $P D(P)$ satisfy $b_{1}=P \leq b_{2}$. Since $P k>P \frac{D(P)}{2}>\underline{\pi}$, then $b_{2} \geq b_{1}=P>\frac{\pi}{\bar{k}}$. By Lemma $2 \sup _{b_{i}} \pi_{i}\left(b_{i}, b_{j}\right)=P D(P), i=1,2$.

Consider the symmetric bid profile $b_{1}=b_{2}=P$. Hence, $\pi_{i}(P, P)=\frac{1}{2} D(P) P, i=1,2$ and

$$
\Gamma_{i}(P, P)=\frac{1}{2} D(P) P, i=1,2 .
$$

Consider the asymmetric bid profiles $b_{1}=P<b_{2}$. Hence, $\pi_{2}\left(P, b_{2}\right)=0$, and

$$
\Gamma_{2}\left(P, b_{2}\right)=D(P) P>\Gamma_{i}(P, P) .
$$

Last, assume $k<D(P)$. The bid profiles yielding joint profits $P D(P)$ must satisfy $b_{1} k+\left[D\left(b_{2}\right)-k\right] b_{2}=D(P) P$ and $D\left(b_{2}\right) \in(k, 2 k)$. It is easy to verify that for $\left(b_{1}, b_{2}\right)$ to belong to this set, we need $b_{1}>\frac{\pi}{\bar{k}}$ and $b_{2} \geq P$. By Lemma $2, \sup _{b_{i}} \pi_{i}\left(b_{1}, b_{2}\right)=$ $b_{j} k, i=1,2, i \neq j$.

Consider the symmetric bid profile $b_{1}=b_{2}=P$. Since $\pi_{i}(P, P)=$ $\frac{1}{2} D(P) P, i=1,2$, we have that

$$
\Gamma_{i}(P, P)=k P-\frac{1}{2} D(P) P, i=1,2 .
$$

Consider the asymmetric bid profiles $\frac{\pi}{k}<b_{1}<P<b_{2}$. We then have $\pi_{1}\left(b_{1}, b_{2}\right)=b_{1} k$ and $\pi_{2}\left(b_{1}, b_{2}\right)=\left[D\left(b_{2}\right)-k\right] b_{2}$. Hence,

$$
\begin{aligned}
& \Gamma_{1}\left(b_{1}, b_{2}\right)=\left[b_{2}-b_{1}\right] k \\
& \Gamma_{2}\left(b_{1}, b_{2}\right)=b_{1} k-\left[D\left(b_{2}\right)-k\right] b_{2}
\end{aligned}
$$

Summing up (8) and (9) and dividing by two,

$$
\frac{\Gamma_{1}\left(b_{1}, b_{2}\right)+\Gamma_{2}\left(b_{1}, b_{2}\right)}{2}=b_{2} k-\frac{D\left(b_{2}\right) b_{2}}{2} .
$$


Comparing (7) and (10), we obtain that for every asymmetric bid profile yielding joint profits $P D(P)$,

$$
\Gamma_{i}(P, P)<\frac{\Gamma_{1}\left(b_{1}, b_{2}\right)+\Gamma_{2}\left(b_{1}, b_{2}\right)}{2}
$$

given that (10) is increasing in $b_{2}$ and $b_{2}>P$.

Now, for $b_{1} \neq \frac{D\left(b_{2}\right) b_{2}}{2 k}, \Gamma_{1}\left(b_{1}, b_{2}\right) \neq \Gamma_{2}\left(b_{1}, b_{2}\right)$. Thus, we either have that $\Gamma_{1}\left(b_{1}, b_{2}\right)>$ $\Gamma_{i}(P, P)$ or $\Gamma_{2}\left(b_{1}, b_{2}\right)>\Gamma_{i}(P, P)$. For $b_{1}=\frac{D\left(b_{2}\right) b_{2}}{2 k}, \Gamma_{1}\left(b_{1}, b_{2}\right)=\Gamma_{2}\left(b_{1}, b_{2}\right)>\Gamma_{i}(P, P)$, which completes the proof.

(ii) Uniform-price auction:

Assume $k \geq D(P)$. The proof for this result is similar to the one for the discriminatory auction.

Assume $k<D(P)$. Given $k<D(P)$, the bid profiles yielding joint profits $P D(P) \in$ $\left(2 \pi, P^{m} D\left(P^{m}\right)\right]$ satisfy $b_{1} \leq b_{2}=P$. We want to show that, among this set of bid profiles, the bid profiles $\left(b_{i}, P\right)$ with $\frac{\pi}{\bar{k}}<b_{i} \leq P$ would lead to higher one-shot deviation gains than the asymmetric bid profiles $\left(b_{i}, P\right)$, with $b_{i} \leq \frac{\pi}{k}$.

W.l.o.g. index firms such that $b_{1} \leq b_{2}$. For the asymmetric bid profiles $b_{1}<P=b_{2}$, we have $\pi_{1}\left(b_{1}, P\right)=P k$, and $\pi_{2}\left(b_{1}, P\right)=[D(P)-k] P$. Consider first the asymmetric bid profiles with $b_{1} \leq \frac{\pi}{\bar{k}}<b_{2}=P$. Following Lemma 2, $\sup _{b_{2}} \pi_{2}\left(b_{1}, b_{2}\right)=\underline{\pi}$, and $\sup _{b_{1}} \pi_{1}\left(b_{1}, P\right)=P k$. We then have that

$$
\Gamma_{2}\left(b_{1}, P\right)=\underline{\pi}-[D(P)-k] P>0=\Gamma_{1}\left(b_{1}, P\right) .
$$

Second, consider the asymmetric bid profiles with $\frac{\pi}{\bar{k}}<b_{1}<b_{2}=P$. Following Lemma 2, $\sup _{b_{i}} \pi_{i}\left(b_{1}, b_{2}\right)=b_{j} k, i=1,2, i \neq j$. Therefore,

$$
\Gamma_{2}\left(b_{1}, P\right)=b_{1} k-[D(P)-k] P>0=\Gamma_{1}\left(b_{1}, P\right) .
$$

Since the value of $\Gamma_{2}\left(b_{1}, P\right)$ in (12) exceeds the one in (11), the bid profiles with $b_{1} \leq$ $\frac{\pi}{\bar{k}}<b_{2}=P$ are the ones that minimize firms' one-shot deviation gains among the set of asymmetric bid profiles.

Last, comparing (11) with the one-shot deviation gains generated by the symmetric bid profile, (7), we get,

$$
\Gamma_{2}\left(b_{1}, P\right)-\Gamma_{i}(P, P)=\underline{\pi}-\frac{1}{2} D(P) P<0, \text { for } b_{1} \leq \frac{\pi}{k},
$$

which completes the proof.

Proof of Proposition 2. The proof for the case in which $k \geq D(0)$ is similar to the Bertrand result.

Assume $k<D(0)$. By Lemma $1, \underline{\pi}=P^{r}\left[D\left(P^{r}\right)-k\right]$. We claim that there exists a unique symmetric equilibrium under the two auction formats; at this equilibrium each firm's profits equal $P^{r}\left[D\left(P^{r}\right)-k\right]$.

Firstly, we show that if $P^{r}=D^{-1}(2 k)$, the bid profiles $b_{i}=D^{-1}(2 k)$, $i=1,2$, constitute an equilibrium under both auction formats. To prove existence, observe that neither firm can increase its profits by bidding above its equilibrium bid, given that $D^{-1}(2 k)$ is the price that maximizes the residual demand faced by the high bidder. Last, note that neither firm can increase its profits by bidding below its equilibrium bid, given that it is already producing at capacity. To prove uniqueness of 
the symmetric equilibrium, note that we cannot have an equilibrium with $b_{1}=b_{2}=b>D^{-1}(2 k)$, given that either firm could increase its profits by slightly undercutting $b$, thus making profits $b k>\frac{1}{2} b D(b)$; we cannot have an equilibrium with $b_{1}=b_{2}=b<D^{-1}(2 k)$, given that either firm could increase its profits by bidding at $D^{-1}(2 k)$, thus making profits $D^{-1}(2 k) k>b k$. Furthermore, it is easy to show that this equilibrium is unique in the discriminatory auction; and that the equilibrium outcome (not the equilibrium) is also unique in the uniform-price auction (see Fabra, von der Fehr and Harbord [2002].)

And secondly, we show that if $P^{r}>D^{-1}(2 k)$, there cannot exist a symmetric equilibrium in pure strategies. At a symmetric equilibrium, with $b_{1}=b_{2}=P$, each firm makes profits $\frac{1}{2} P D(P)$. If $P \leq \frac{\pi}{\bar{k}}$, a firm could increase its profits by bidding at $P^{r}$, to obtain profits $\underline{\pi}>\frac{1}{2} P D(P)$; if $P>\frac{\pi}{k}$, a firm could increase its profits by slightly undercutting $P$, thus obtaining profits $P k>\frac{1}{2} P D(P)$. Thus the unique symmetric equilibrium is in mixed strategies.

Let $F_{i}(p)=\operatorname{Pr}\left\{b_{i} \leq p\right\}$ denote the equilibrium mixed-strategy of firm $i, i=1,2$, with $f_{i}(p)=F_{i}(p)$, and let $\Omega_{i}$ be the support of $F_{i}$. Standard arguments imply that $\Omega_{1} \cap \Omega_{2}=(p, \bar{p})$ (or, $[p, \bar{p})$ ), and that $F_{1}$ and $F_{2}$ do not have mass points on $[p, \bar{p})$. We want to demonstrate that at the unique symmetric mixed-strategy equilibrium, firm $i$ 's expected profits are given by $P^{r}\left[D\left(P^{r}\right)-\mathrm{k}\right] i=1,2$, under the two auction formats.

Uniform-price auction: Firm $i$ 's expected profits when bidding $p$ can be written as,

$$
\pi_{i}^{u}(p)=p[D(p)-k] F(p)+\int_{p}^{\bar{p}} v k f(v) d v
$$

On $(\underline{p}, \bar{p})$, strategies must satisfy the following differential equations:

$$
F(p)[D(p)-k+p D(p)]-f(p) p[2 k-D(p)]=0, i=1,2 .
$$

The first element on the left-hand side of (13) represents the gain to a firm from the resulting increase in the price received in the event that the rival bids below. The second element represents the loss from reducing the chance of being despatched at full capacity instead of serving the residual demand only (the difference being $k-[D(p)-k]=2 k-D(p))$. On the interior of the support of the mixed strategies the net gain from raising the bid marginally must be zero. In particular, the first order condition $\frac{\partial \pi_{i}^{u}(p)}{\partial p}=0$ evaluated at $\bar{p}$ becomes $D(\bar{p})-k+\bar{p} D(\bar{p})=0$, which determines $\bar{p}$ uniquely, $\bar{p}=P^{r}$. Since when a firm is bidding at $P^{r}$ the rival is bidding below with probability one, it follows that expected profits are given by $P^{r}\left[D\left(P^{r}\right)-k\right]$.

Discriminatory auction: Firm $i$ 's, $i=1,2$, profit when bidding $p$ may be written

$$
\pi_{i}^{d}(p)=p\left\{F_{j}(p)[D(p)-k]+\left[1-F_{j}(p)\right] k\right\} .
$$

A necessary condition for firm $i$ to be indifferent between any price in $\Omega_{i}$ is that, for all $p \in \Omega_{i}, \pi_{i}^{d}(b)=\bar{\pi}_{i}$, implying

$$
F_{j}(p)=\frac{k}{2 k-D(p)}\left[1-\frac{\bar{\pi}_{i}}{p k}\right] .
$$


The boundary condition $F_{j}(\bar{p})=1$ implies

$$
\bar{\pi}_{i}=[D(\bar{p})-k] \bar{p} .
$$

We must also have $\frac{\partial \pi_{i}^{d}(p)}{\partial p}=0$; in particular,

$$
\bar{p}=P^{r},
$$

so that

$$
\bar{\pi}_{i}=\left[D\left(P^{r}\right)-k\right] P^{r} .
$$

Finally, the condition $F_{j}(\underline{b})=0$ implies

$$
\underline{b}=\frac{1}{k}\left[D\left(P^{r}\right)-k\right] P^{r}=\frac{\pi}{k} .
$$

Proof of Proposition 3. W.1.o.g. let $b_{1} \leq b_{2}$, and index firm $i(j), i=1,2, i \neq j$, as firm 1 (2) in period $t$, if $b_{i}^{c}(t)=b_{1} \leq b_{j}^{c}(t)=b_{2}$. In words, firm 1 is the low bidder, and firm 2 is the high bidder.

Throughout the proof, we will assume that, in every period, firms can observe the realization of some public randomization device which selects the firm that will play the role of the low bidder in a given period. We will allow the process to depict correlation across time in the following way: if firm $i$ has been selected to play the role of the low bidder in period $t$, then in period $t+1$, it will be selected to play the role of the low bidder with probability $\alpha$ and the role of the high bidder with probability $(1-\alpha)$, with $\alpha \in[0,1] .{ }^{12}$ To simplify notation, let $V_{1}(b ; \alpha)$ (and alternatively $V_{2}(b ; \alpha)$ ) denote the present discounted value in period $t$ of firm $i$ 's (firm $j$ 's) profits from period $t+1$ into the future if firm $i$ has played the role of the low (high) bidder in period $t$. Last, let $\pi_{1}\left(\pi_{2}\right)$ denote the profits of firm $i$ in a given period in which it plays the role of the low (high) bidder. We thus can construct $V_{1}$ and $V_{2}$ as follows,

$$
\begin{aligned}
& V_{1}(b ; \alpha)=\delta\left\{\alpha\left[\pi_{1}+\delta V_{1}(b ; \alpha)\right]+[1-\alpha]\left[\pi_{2}+\delta V_{2}(b ; \alpha)\right]\right\} \\
& V_{2}(b ; \alpha)=\delta\left\{\alpha\left[\pi_{2}+\delta V_{2}(b ; \alpha)\right]+[1-\alpha]\left[\pi_{1}+\delta V_{1}(b ; \alpha)\right]\right\}
\end{aligned} .
$$

With some algebra,

$$
\begin{aligned}
& V_{1}(b ; \alpha)=X(\alpha)\left\{\pi_{2}+\left[\pi_{1}-\pi_{2}\right] \alpha+[1-2 \alpha] \pi_{1} \delta\right\} \\
& V_{2}(b ; \alpha)=X(\alpha)\left\{\pi_{1}-\left[\pi_{1}-\pi_{2}\right] \alpha+[1-2 \alpha] \pi_{2} \delta\right\}
\end{aligned}
$$

Note that for the symmetric bid profiles we have

$$
V_{1}(P, P)=V_{2}(P, P)=\frac{\delta}{1-\delta} \frac{D(P) P}{2}
$$

(i) Discriminatory auction: The method of proof will be to show that for every asymmetric path of bid profiles, with $b_{1}<b_{2}$, yielding joint profits $P D(P)$ in every

\footnotetext{
${ }^{12}$ Note that this assumption is without loss of generality, as it encompasses all possibilities; in particular, if $\alpha=0$ firms play the roles of the high and low bidder in deterministic turns, if $\alpha=1$ firms do not change roles over time (e.g., the low bidder keeps on being the low bidder for ever), and if $\alpha=\frac{1}{2}$ the process is stationary (i.e., the public signal is i.i.d.), with a firm's role in the current period having no impact on its next period's role.
} 
period, the following condition is satisfied:

$$
\begin{array}{lll}
\min \left\{V_{i}(b ; \alpha)-\Gamma_{i}(b)\right\}<V_{i}(P, P)-\Gamma_{i}(P, P) & \text { if } & \Gamma_{i}(b)>0, i=1,2 \\
V_{i}(b ; \alpha)-\Gamma_{i}(b)<V_{i}(P, P)-\Gamma_{i}(P, P) & \text { if } & \Gamma_{j}(b)>0, i \neq j .
\end{array}
$$

Since this implies that the critical discount factor that makes the relevant incentive compatibility constraint binding is lower under the symmetric path than under any other path yielding joint profits $P D(P)$ in every period, this is sufficient to prove Proposition $3(i)$.

First, assume $k \geq D(P)$. Consider the asymmetric bid profiles yielding joint profits $D(P) P$, i.e. $b_{1}=P<b_{2}$. Firms' one-shot deviation gains are given by

$$
\begin{aligned}
& \Gamma_{1}\left(P, b_{2}\right)=D\left(b_{2}\right) b_{2}-D(P) P \\
& \Gamma_{2}\left(P, b_{2}\right)=D(P) P
\end{aligned} .
$$

By setting $b_{2}$ arbitrarily close to $P$, the low bidder's one-shot deviation gains are driven down to zero. Thus, the relevant incentive compatibility constraint is that of the high bidder. We want to choose $\alpha$ so as to maximize $V_{2}\left(P, b_{2} ; \alpha\right)-\Gamma_{2}\left(P, b_{2}\right)$. Note that $V_{2}(b$; $\alpha)-\Gamma_{2}(b)$ is decreasing in $\alpha$ : the greater $\alpha$, the greater the probability that the high bidder today will keep on playing the role of the high bidder tomorrow, thus earning zero profits rather than $D(P) P$. Hence, it is optimal to set $\alpha=0$, i.e. to let firms play the roles of the high and low bidder in deterministic turns. Therefore, for the asymmetric bid profiles $b_{1}=P<b_{2}$,

$$
V_{2}\left(P, b_{2} ; 0\right)-\Gamma_{2}\left(P, b_{2}\right)=\frac{\delta}{1-\delta^{2}} D(P) P-D(P) P .
$$

Consider the symmetric bid profiles $b_{1}=b_{2}=P$. Firms' one-shot deviation gains are given by (6). Using (15), we then have

$$
V_{i}(P, P)-\Gamma_{i}(P, P)=\frac{\delta}{1-\delta} \frac{D(P) P}{2}-\frac{D(P) P}{2} .
$$

Simple algebra shows that (18) exceeds (17). Hence, condition (16) is satisfied.

Last, assume $k<D(P)$. Consider the asymmetric bid profiles yielding joint profits $D(P) P$. As in the proof of Lemma 3, these must satisfy $b_{1} k+\left[D\left(b_{2}\right)-k\right] b_{2}=D(P) P$ and $k<D\left(b_{2}\right)$. Firms' one-shot deviation gains from the asymmetric bid profiles are as in (8) and (9). Since both firms have positive one-shot deviation gains, the objective is to choose $\alpha$ so as to maximize the $\min \left\{V_{1}(b ; \alpha)-\Gamma_{1}(b), V_{2}(b ; \alpha)-\Gamma_{2}(b)\right\}$. Note that $V_{2}(b ; \alpha)-\Gamma_{2}(b)$ is decreasing in $\alpha$ : the greater $\alpha$, the greater the probability that the high bidder today will keep on playing the role of the high bidder tomorrow, thus earning profits $\left(D\left(b_{2}\right)-k\right) b_{2} \leq b_{1} k$. For the opposite reason, $V_{1}(b ; \alpha)-\Gamma_{1}(b)$ is increasing in $\alpha$. Therefore, we have to find the value of $\alpha=\widehat{\alpha}$, such that $V_{1}(b ; \widehat{\alpha})-$ $\Gamma_{1}(b)=V_{2}(b ; \widehat{\alpha})-\Gamma_{2}(b)$. Using (14), simple algebra shows that

$$
\widehat{\alpha}=\frac{1}{2}\left[1-\frac{1}{\delta} \frac{\Gamma_{2}(b)-\Gamma_{1}(b)}{\Gamma_{1}(b)}\right] .
$$

And,

$$
V_{i}(b ; \widehat{\alpha})-\Gamma_{i}(b)=\frac{\delta}{1-\delta} \frac{D(P) P}{2}-\left[b_{2} k-\frac{D\left(b_{2}\right) b_{2}}{2}\right], i=1,2 .
$$


Since we must have $\alpha \in[0,1)$, then the constrained solution equals (19) if $\widehat{\alpha} \in[0,1)$, and is lower than (19) otherwise. Hence, showing that $V_{i}(P, P)-\Gamma_{i}(P, P)$ exceeds (19) is sufficient to prove the statement.

Firms' one-shot deviation gains from the symmetric bid profile are as in (7). Hence,

$$
V_{i}(P, P)-\Gamma_{i}(P, P)=\frac{\delta}{1-\delta} \frac{D(P) P}{2}-\left[P k-\frac{D(P) P}{2}\right], i=1,2 .
$$

Since (19) is decreasing in $b_{2}$ and $b_{2}>P$, then (20) exceeds (19). Therefore, condition (16) is satisfied, which completes the proof.

(ii) Uniform-price auction: For the case in which $k<D(P)$, the proof is similar as the proof for the discriminatory auction, given that in this case the two auction formats are equivalent. Assume $k<D(P)$. The paths of bid profiles satisfying $b_{1}(t)=b_{2}(t+1) \leq$ $\frac{\pi}{\bar{k}}<b_{2}(t)=b_{1}(t+1)=P \forall t \geq 1$ maximize the continuation value of the only firm that has incentives to deviate, i.e. the high bidder (it is optimal to set $\alpha=0$ ), and drive its oneshot deviation gains to its minimum level (Lemma 3).

Proof of Proposition 4. To prove Proposition 4, some existence results are needed.

\section{Lemma A1.}

(i) There exists $\underline{\delta} \in\left[0, \frac{1}{2}\right]$ such that there exists a symmetric path of bid profiles that is sustainable for all $\delta \geq \underline{\delta}$.

(ii) There exists $\bar{\delta} \in[\underline{\delta}, 1)$ such that monopoly profits can be sustained through symmetric bidding if and only if $\delta \geq \bar{\delta}$.

Proof of Lemma A1. (i) From the proof of Lemma 3, if $k<D(0), b_{i}(t)=0, i=1,2$, $t \geq 1$, constitutes a one-shot Nash equilibrium and thus a Subgame Perfect Equilibrium of the infinitely repeated game. Similarly, if $P^{r}=D^{-1}(2 k), b_{i}(t)=D^{-1}(2 k), i=1,2$, $t \geq 1$, constitutes a one-shot Nash equilibrium and thus a Subgame Perfect Equilibrium of the infinitely repeated game. Thus, in these two cases, $\underline{\delta}=0$.

Now, suppose $P^{r}>D^{-1}(2 k)$. We claim that $b_{i}(t)=P^{r}, i=1,2, t \geq 1$, constitutes a Subgame Perfect Equilibrium of the infinitely repeated game. Firms' symmetric incentive compatibility constraint evaluated at $\left(P^{r}, P^{r}\right)$ can be written as

$$
P^{r} k-\frac{1}{2} D\left(P^{r}\right) P^{r} \leq \frac{\delta}{1-\delta}\left[\frac{1}{2} D\left(P^{r}\right) P^{r}-\underline{\pi}\right] .
$$

Since, by Lemma $1, \underline{\pi}=\left[D\left(P^{r}\right)-k\right] P^{r}$, the above equation can be written as

$$
P^{r}\left[k-\frac{1}{2} D\left(P^{r}\right)\right] \leq \frac{\delta}{1-\delta} P^{r}\left[k-\frac{1}{2} D\left(P^{r}\right)\right]
$$

and is satisfied if $\delta \geq \frac{1}{2}$. Thus $\underline{\delta}=\frac{1}{2}$.

(ii) If $k \geq D(0)$, the incentive compatibility condition evaluated at the symmetric bid profile $(P, P)$ can be written as

$$
\left[\frac{1}{2} D(P) P\right] \geq \frac{\delta}{1-\delta}\left[\frac{1}{2} D(P) P\right]
$$

and is satisfied for all $P$, and $P^{m}$ in particular, if and only if $\delta \geq \frac{1}{2}$. Thus $\bar{\delta}=\frac{1}{2}$. 
Assume $k<D(0)$ and $P^{m}>D^{-1}(2 k)$. The (symmetric) incentive compatibility condition evaluated at the monopoly price takes the following form,

$$
P^{m} \min \left\{k, D\left(P^{m}\right)\right\}-\frac{1}{2} D\left(P^{m}\right) P^{m} \leq \frac{\delta}{1-\delta}\left[\frac{1}{2} D\left(P^{m}\right) P^{m}-\left[D\left(P^{r}\right)-k\right] P^{r}\right] .
$$

First note that the 1.h.s. of (21) is strictly positive, finite, and independent of $\delta$; the r.h.s. of (21) is strictly increasing in $\delta$. For $\delta=\underline{\delta}=\frac{1}{2}$, equation (21) can be rewritten as

$$
\frac{1}{2} D\left(P^{m}\right) P^{m} \leq \frac{1}{2} D\left(P^{m}\right) P^{m}-\left[D\left(P^{r}\right)-k\right] P^{r} \text { for } k \geq D\left(P^{m}\right)
$$

and

$$
\left[D\left(P^{r}\right)-k\right] P^{r} \leq\left[D\left(P^{m}\right)-k\right] P^{m} \text { for } \frac{1}{2} D\left(P^{m}\right)<k<D\left(P^{m}\right)
$$

Both equations are clearly not satisfied. For $\delta \rightarrow 1$, the r.h.s. of (21) tends to infinity; hence $(21)$ is satisfied. By the continuity of the r.h.s. of (21) in $\delta$ it follows that there exists $\bar{\delta} \in(\underline{\delta}, 1)$ such that monopoly profits are sustainable in every period through symmetric bidding. Last, assume $P^{m}=D^{-1}(2 k)$. Clearly, the monopoly price is sustainable as a (symmetric) one-shot Nash equilibrium (see the proof of Lemma 3 ). Hence, $\bar{\delta}=0$.

With this, we are now able to prove Proposition 4.

For given $\delta \in(0,1)$, let $P^{*}$ be the highest sustainable price under symmetric bidding. For $\delta \in[\bar{\delta}, 1), P^{*}=P^{m}($ Lemma A1 $(i i))$; for $\delta \in(0, \underline{\delta}), P^{*}<P^{r}(\operatorname{Lemma} \mathrm{A} 1(i))$; for $\delta \in[\underline{\delta}, \bar{\delta}), P^{*}$ is the highest price that satisfies

$$
P^{*} \min \left\{k, D\left(P^{*}\right)\right\}-\frac{1}{2} D\left(P^{*}\right) P^{*}=\frac{\delta}{1-\delta}\left[\frac{1}{2} D\left(P^{*}\right) P^{*}-\underline{\pi}\right]
$$

Discriminatory auction: Since symmetric bidding is optimal in the discriminatory auction for all $k$ (Proposition 3 ), it follows that $P^{*} D\left(P^{*}\right)$ is the highest sustainable perperiod profit level in the discriminatory auction.

Uniform-price auction: First, it is clear that the highest sustainable profit level in the uniform-price auction is at least equal to $P^{*} D\left(P^{*}\right)$ given that firms may choose to collude on the path of symmetric bid profiles. Second, we proceed by showing that the highest sustainable profit level in the uniform-price auction is greater than $P^{*} D\left(P^{*}\right)$ if and only if $k<D(0)$ and $\delta \in(0, \bar{\delta})$.

(If) First, assume $k<D(0)$ and $\delta \in[\underline{\delta}, \bar{\delta})$. From (22) it is easy to show that for $\delta \in[\underline{\delta}, \bar{\delta})$, we have $D\left(P^{*}\right)>k$. By Proposition 3 , in the uniform-price auction the optimal collusive scheme yielding joint profits $P^{*} D\left(P^{*}\right)$ in every period is asymmetric. This implies that for a given discount factor $\delta \in[\underline{\delta}, \bar{\delta})$, the high bidder's incentive compatibility constraint evaluated at the optimal collusive scheme yielding joint profits $P^{*} D\left(P^{*}\right)$ in every period would be satisfied with slack. Hence, the collusive profit level in the uniform-price auction can be raised over $P^{*} D\left(P^{*}\right)$ while still making the incentive compatibility constraints satisfied.

Second, assume $k<D(0)$ and $\delta \in(0, \underline{\delta})$. Note that this case does not arise for capacity values such that $P^{m}=D^{-1}(2 k)$ given that in this case $\underline{\delta}=0$. For $P^{m}>D^{-1}$ (2k), $\underline{\delta}=\frac{1}{2}$, and $P^{*}<P^{r}$. Given that $D\left(P^{r}\right)>k$, in the uniform-price auction the optimal collusive scheme yielding joint profits $P^{r} D\left(P^{r}\right)$ in every period is asymmetric 
(Proposition 3). For the same reasoning as above, the collusive profit level can be raised over $P^{r} D\left(P^{r}\right)>P^{*} D\left(P^{*}\right)$ while still making the incentive compatibility constraints satisfied.

(Only if) Assume $k \geq D(0)$. For all $\delta \in(0,1)$, given that $P^{*} \geq 0$, then $k \geq D\left(P^{*}\right)$. By Proposition 3, in the uniform-price auction the optimal collusive scheme yielding joint profits $P^{*} D\left(P^{*}\right)$ in every period is symmetric. Hence, the highest level of sustainable joint profits in the uniform-price auction also equals $P^{*} D\left(P^{*}\right)$, as in the discriminatory auction.

(Only if) Assume $\delta \in[\bar{\delta}, 1)$. Hence $P^{*}=P^{m}$. Since profits cannot be raised over the monopoly level, it follows that the highest level of sustainable joint profits in the uniform-price auction also equals $P^{*} D\left(P^{*}\right)$, as in the discriminatory auction.

\section{REFERENCES}

Aoyagi, M., 2000, 'Bid Rotation and Collusion in Repeated Auctions', CMPO Working Paper Series, No. 00/29

Athey, S. and Bagwell, K., 2001, 'Optimal Collusion with Private Information', Rand Journal of Economics, 3(32), pp. 428-465.

Back, K. and Zender, J. F., 1993, 'Auctions of Divisible Goods: On the Rationale for the Treasury Experiment', The Review of Financial Studies, 6(4), pp. 733-764.

Baldwin, L. H., Marshall, R. C. and Richard, J. -F., 1997, 'Bidder Collusion at Forest Service Timber Sales', Journal of Political Economy, 105, pp. 657-699.

Binmore, K. and Swierzbinski, J., 2001, 'Treasury Auctions: Uniform or Discriminatory?' Review of Economic Design, 5, pp. 387-410.

Brock, W. and Scheinkman, J., 1985, 'Price Setting Supergames with Capacity Constraints', Review of Economic Studies, LII, pp. 371-382.

Fabra, N., von der Fehr, N. -H. M. , and Harbord, D. C., 2002a, 'Designing Electricity Auctions: Uniform, Discriminatory and Vickrey' (Universidad Carlos III de Madrid and University of Oslo, Mimeo.).

Fabra, N., von der Fehr, N. -H. M. and Harbord, D. C., 2002b, 'Modelling Electricity Auctions', Electricity Journal, 15(7), pp. 72-81.

Goswami, G., Thomas, N. and Rebello, M., 1996, 'Collusion in Uniform-Price Auctions: Experimental Evidence and Implications for Treasury Auctions', Review of Financial Studies Fall, 9(3), pp. 757-785.

Klemperer, P., 2002, 'What Really Matters in Auction Design', Journal of Economic Perspectives, 16(1), pp. 169-190.

Kreps, D. and Scheinkman, J., 1983, 'Quantity Precommitment and Bertrand Competition Yield Cournot Outcomes', Bell Journal of Economics, 14(2), pp. 326-337.

LaCasse, C., 1995, 'Bid Rigging and the Threat of Government Prosecution', Rand Journal of Economics, 26(3), pp. 398-417.

Lambson, V. E., 1988, 'Optimal Penal Codes in Price-Setting Supergames With Capacity Constraints', Review of Economic Studies, 54, pp. 385-97.

Nyborg, K. and Sundaresan, S., 1996, 'Discriminatory versus Uniform Treasury Auctions: Evidence From When Issued Transactions', Journal of Financial Economics, 42, pp. 63-104.

McAfee, P. R. and McMillan, J., 1992, 'Bidding Rings', American Economic Review, 82, pp. 579-599.

McMillan, P. R., 1991, 'Dango: Japan's Price Fixing Conspiracies', Economics and Politics, 3, pp. 201-218.

Ofgem 2002, A Review of the First Year of NETA. A Review Document, Vol. 1 (Birmingham). 
Pesendorfer, M., 2000, 'A Study of Collusion in First Price Auctions', Review of Economic Studies, 67, pp. 381-411.

Porter, R. H. and Zona, J. D., 1993, 'Detection of Bid Rigging in Procurement Auctions', Journal of Political Economy, 101, pp. 518-538.

Rotemberg, J. and Saloner, G., 1986, 'A Supergame-Theoretic Model of Price Wars during Booms', American Economic Review, 73, pp. 390-407.

Skrzypacz, A. and Hopenhayn, I., 1999, 'Bidding Rings in Repeated Auctions', Rochester Center for Economic Research Working Paper, No. 463

Staiger, R. W. and Wolak, F. A., 1992, 'Collusive Pricing with Capacity Constraints in the Presence of Demand Uncertainty', Rand Journal of Economics, 23(2), pp. 203-219.

von Ungern-Sternberg, T., 1988, 'Cartel Stability in Sealed-Bid Second Price Auctions', Journal of Industrial Economics, 36, pp. 351-358. 